\title{
Polyamide Nanofiber-Based Air Filters for Transparent Face Masks
}

\author{
Joshua Avossa, Till Batt, Thierry Pelet, Sacha P. Sidjanski, Klaus Schönenberger, and René M. Rossi*
}

Cite This: ACS Appl. Nano Mater. 2021, 4, 12401-12406

Read Online

Wlll Metrics \& More

Article Recommendations

Supporting Information

ABSTRACT: Transparent face masks are the ultimate solution for improving communication during pandemic times while at the same time slowing the spread of pathogens. Here, we demonstrate an easily scalable process consisting of directly electrospinning polyamide nanofibers onto a mechanical stable substrate made of poly(lactic acid) by a needleless setup for the production of transparent filter material. Filtration tests against $\mathrm{NaCl}$ and fructose aerosols and pressure drop tests were performed and compared with the European standard for medical face masks (EN 14683:2019) and the Swiss rule for community masks (SNR 30000:2021). The filter showed outstanding transparency $(\sim 70 \%$ transmittance in the visible-light range), $89 \%$ filtration efficiency against $\mathrm{PM}_{1.0}$, and a pressure drop of $6.5 \mathrm{~Pa} / \mathrm{cm}^{2}$.

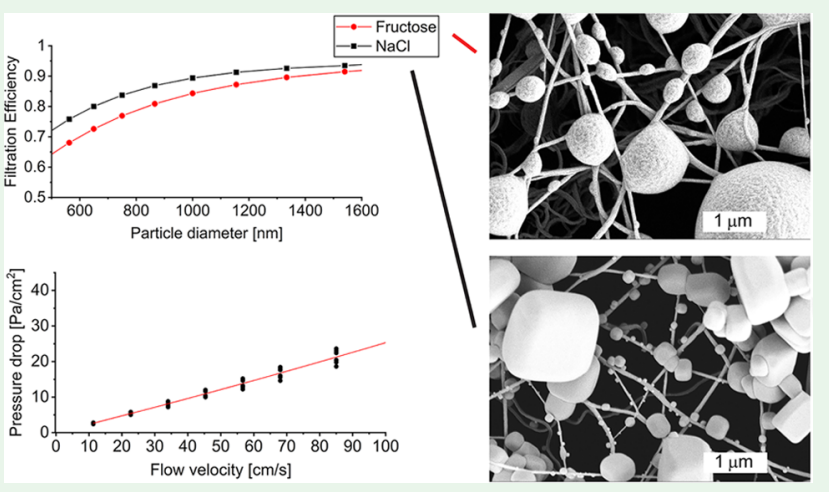

KEYWORDS: transparent mask, air filter, nanofibers, fructose aerosol, needleless electrospinning, green solvents, PA11, Nylon-11

\section{INTRODUCTION}

Because of the COVID-19 pandemic, the importance of wearing face masks became clear on a global level; especially in closed environments (transportation means, schools, offices, etc.), where physical distancing rules cannot be followed and ventilation is on a lower level, masks are very effective. Face masks are intended to prevent the spread of virus-containing droplets and aerosols caused by coughing, sneezing, speaking, or breathing. ${ }^{1}$ They are usually based on fiber air filters made of melt-blown polypropylene (PP) protected by two layers of a $\mathrm{PP}$ spunbond. Because most of these commercial filter layers for face masks are composed of fibers with diameters in the micrometric range, they completely scatter and reflect light. Wearers experience more difficult communication and social interaction because of more limited recognition of facial expressions and emotions, as more than $50 \%$ of the face is covered, exacerbating the sense of alienation already created by lockdowns and restrictions. Some of the most affected people are children because of their natural need for human contact. ${ }^{2}$ In addition, elderly persons with limited hearing and deaf-mute persons rely on facial expressions for communication. Consequently, they are not able to communicate at all with the existing commercial face masks. Therefore, the demand in society for transparent face masks rapidly increased for the sake of the most vulnerable people. Electrospinning (ES) is a promising technology to produce such transparent filters. ES enables the formation of polymeric fibers smaller than tens of nanometers with a relatively small standard deviation of the fiber diameter, which implies low scattering of light and good transparency.
Several attempts at producing transparent filters have been made. He et al. showed that the performance of a substrate poly(lactic acid) (PLA) 3D-printed on a PLA electrospun filtering layer reached almost $70 \%$ filtration efficiency (FE). ${ }^{3}$ Transparent filters of copper-coated polyacrylonitrile electrospun fibers were tested as an air filter by the application of a voltage $^{4}$ or against charged aerosol particles and grounding of the filter. ${ }^{5}$ Mikheev et al. formed, within a hole in a dielectric screen, an almost invisible nanomat layer using a coaxial spinneret ES setup with superior FE. ${ }^{6}$ Polyurethane, ${ }^{7}$ poly(methyl methacrylate)-poly(dimethylsiloxane), ${ }^{8}$ Nylon-6, ${ }^{9,10}$ Nylon-66, ${ }^{11}$ cross-linked poly(vinyl alcohol)-sodium lignosulfonate, $^{12}$ polyacrylonitrile, ${ }^{13,14}$ and PLA-poly(methyl methacrylate) fibers ${ }^{15}$ were tested against $2.5 \mu \mathrm{m}$ particles for transparent air filter application. Cheng et al. produced Nylon6,6 electrospun fibers on a copper mesh with excellent FE performances against $0.3-5.0 \mu \mathrm{m}$ particles and transparency. ${ }^{16}$ Some approaches are not upscalable because of the use of a syringe setup ${ }^{3-6,8,10-16}$ and therefore not feasible for industrial-scale production of face masks. However, other approaches used a large-scale setup, but the fibers were electrospun onto a conductive mesh and then transferred to a plastic substrate or a frame focusing upon PM2.5 removal for air filter application. ${ }^{7,9}$

Received: September 8, 2021

Accepted: September 23, 2021

Published: November 2, 2021 


\section{Scheme 1. Scheme of the Production Steps of the Transparent Filter Material ${ }^{a}$}

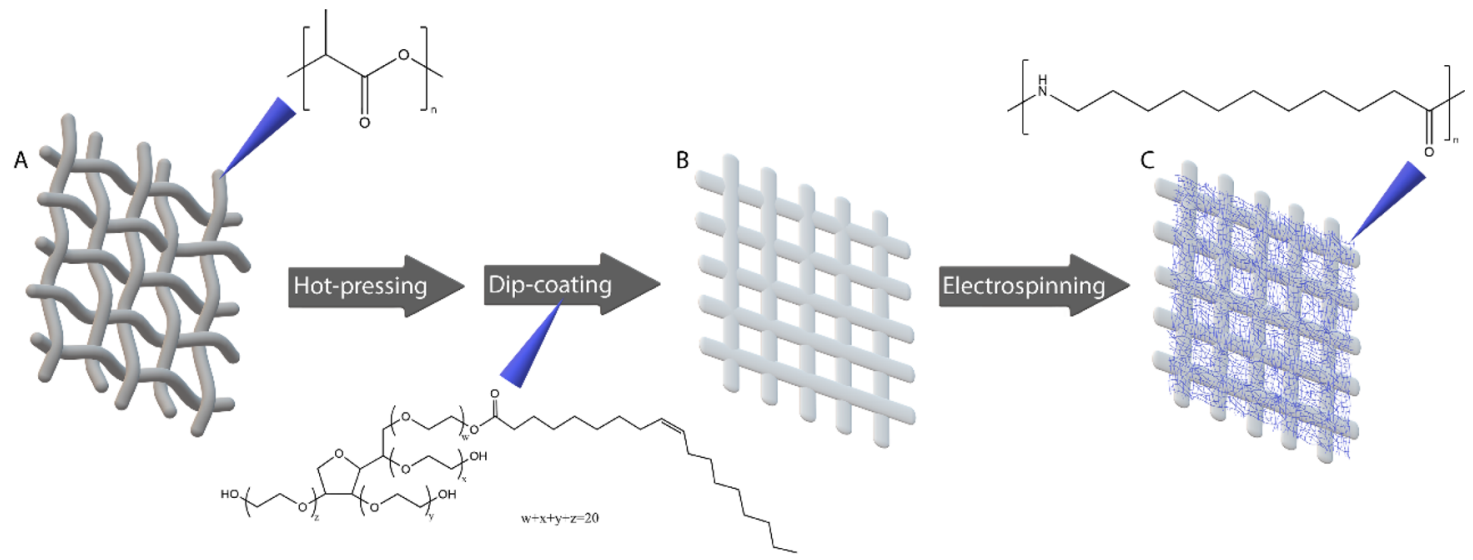

${ }^{a_{T}}$ The commercial PLA mesh (A) was hot-pressed and then dip-coated with a TWEEN 80 solution to obtain a flat and less electrostatic substrate (B) to directly electrospin PA11 nanofibers (C).

In our study, we focused on the development of a freestanding filter based on a Polyamide-11 (PA11) nanofiber supported by PLA mesh (PLA-PA11) as a possible substrate for the production of transparent face masks (all of the production steps of the PLA-PA11 filter material are depicted in Scheme 1). PLA-PA11 was prepared in a single step (i.e., without using intermediate steps for transfer of the filtering material onto the support) by directly ES PA11 onto the PLA support using a preindustrial pilot-scale setup, keeping in mind the possibility of further scaling up the process. To the best of our knowledge, this is the first time that a transparent filter material was prepared by direct spinning onto a transparent substrate using a pilot-scale setup.

The PLA-PA11 material was characterized using scanning electron microscopy (SEM) and UV-vis spectrophotometry to quantify the transparency, FE against fructose and sodium chloride $(\mathrm{NaCl})$ aerosols, and pressure drop. Commercial face masks are usually benchmarked against the existing standards; therefore, the methods used in this work, together with the FE and pressure drop values characterizing the performance of the PLA-PA11 filtering material as a face mask, are compared with the standard for medical face masks (EN 14683:2019), ${ }^{17}$ as well as the new Swiss rule for community masks (SNR 30000:2021). ${ }^{18}$

\section{EXPERIMENTAL SECTION}

Materials. TWEEN 80, D-fructose, sodium chloride $(\mathrm{NaCl})$, Polyamide-11 (PA11), and anisole were purchased from Merck, Germany (previously Sigma-Aldrich); formic acid (99-100\% purity) was purchased from VWR, Switzerland; the PLA mesh was purchased from Sichuan KST Automatic Equipment, China; baking paper substrate was purchased from Elmarco, Czech Republic. All of the products were used as received without further treatment or purification.

Substrate Preparation. The PLA mesh was pressed with a 50 bar pressure for $30 \mathrm{~s}$ at $120{ }^{\circ} \mathrm{C}$ to increase the transparency and reduce the PLA fiber movement, likely causing the formation of holes on the PA11 filter.

Because PLA has intrinsically antistatic properties, thus preventing fiber deposition during the ES process, a skin-compatible surfactant (TWEEN 80) acting as an antistatic substance (thanks to the water attraction ability) was chosen to coat the mesh employing a dipcoating technique, which was performed using $1.0 \mathrm{wt} \%$ TWEEN 80 in ethanol.
ES. The pressed PLA-TWEEN 80 was coated with PA11 electrospun fibers $\left(0.1 \mathrm{~g} / \mathrm{m}^{2}\right)$ using a solvent mixture previously reported by Meireman et al. ${ }^{19}$ and considered "green" according to the GSK classification. ${ }^{20} \mathrm{~A}$ solution of 6 wt \% PA11 in formic acid:anisole $=60: 40$ by volume was used for the production of electrospun nanofibers. The solvent mixture is safe to handle at room temperature during the ES process because of high flash points (52 and $69{ }^{\circ} \mathrm{C}$ for anisole and formic acid, respectively). The pressed PLA-TWEEN 80 was then attached to the baking paper (substrate from Elmarco) using double-sided tape, and ES was performed using a pilot-scale setup (Nanospider from Elmarco, Czech Republic). The solution was loaded into the carriage, which fit with the single-wire needleless setup of Nanospider (video available ${ }^{21}$ ). The applied voltage was $2.5 \mathrm{kV} / \mathrm{cm}$, and the temperature and relative humidity were regulated at $\sim 20{ }^{\circ} \mathrm{C}$ and $\sim 20 \%$, respectively, with a constant flow stream of $100 \mathrm{~m}^{3} / \mathrm{h}$.

UV-Vis Spectrophotometry. The transmittance was measured using a Cary 4000 UV-vis spectrophotometer from Agilent. The samples are placed orthogonal to the incident light using a solid sample holder (Agilent) with an aperture mask of $\sim 1 \mathrm{~cm}^{2}$.

SEM. To assess the morphological properties of the electrospun nanofibers, the specimens were coated with $10 \mathrm{~nm}$ of gold/palladium (80:20) and analyzed using an S-4800 scanning electron microscope (Hitachi High-Technologies, USA). The average diameter of the nanofibers was calculated using ImageJ software (ImageJ2, USA) by measuring over 100 fiber diameters on different SEM pictures.

FE. The FE setup (Figure 1) is composed of an aerosol generator (PALAS AGK2000), a corona-discharge neutralizer (PALAS CD2000), a sample holder, pumps, and a particle analyzer (Cambustion DMS500). The sample holder for FE testing provides an effective filter surface of $16.6 \mathrm{~cm}^{2}$. Through the surface, the flow

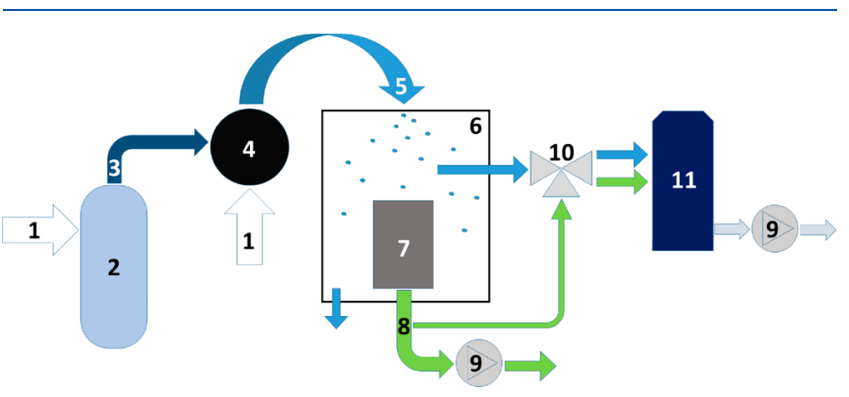

Figure 1. Scheme of the FE test equipment: (1) dry air; (2) aerosol generator; (3) aerosol; (4) charge neutralizer; (5) aerosol; (6) container; (7) sample holder; (8) filtered aerosol; (9) pump; (10) valve; (11) analyzer. 

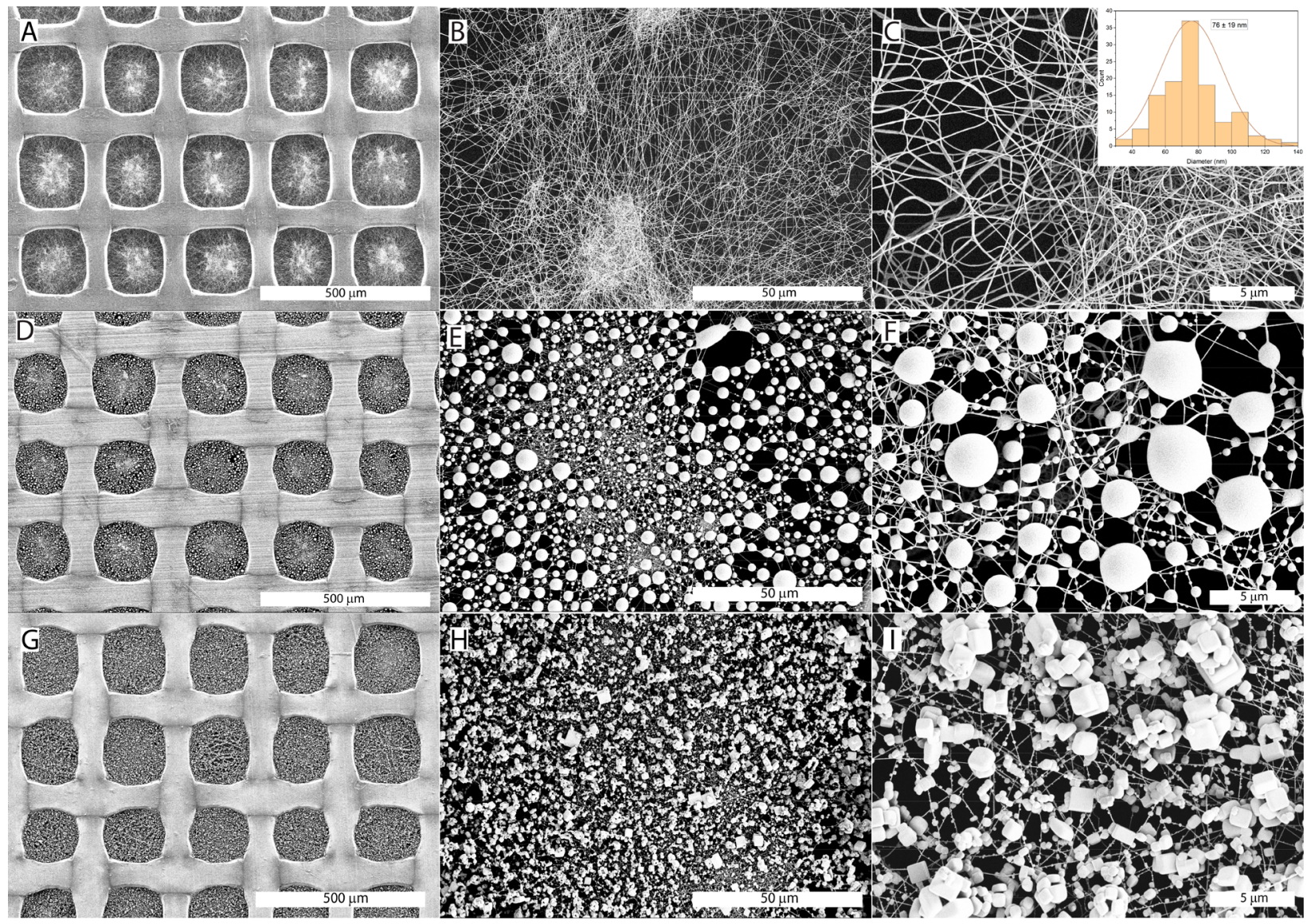

Figure 2. SEM micrographs of the PLA-PA11 filter at $100 \times(\mathrm{A}), 1000 \times(\mathrm{B})$, and $5000 \times(\mathrm{C})$ of magnification, with an inset in part C representing the diameter distribution of the fibers collected from the SEM micrographs; PLA-PA11 after fructose areosol tests at 100× (D), 1000× (E), and $5000 \times(\mathrm{F})$ of magnification; PLA-PA11 after $\mathrm{NaCl}$ aerosol tests at $100 \times(\mathrm{G}), 1000 \times(\mathrm{H})$, and $5000 \times(\mathrm{I})$ of magnification.

velocity was $8 \mathrm{~cm} / \mathrm{s}$, mimicking the human breathing velocity at light physical exertion. Aerosols were produced from freshly prepared solutions of fructose and $\mathrm{NaCl}$ with a concentration of $1.96 \mathrm{wt} \%$ water. $\mathrm{NaCl}$ and fructose aerosol concentrations were measured and reported Figure S1.

The $\mathrm{FE}$ value is measured according to the equation

$$
\mathrm{FE}=1-\frac{C}{C_{0}}
$$

The particle FE is determined after a steady-state concentration of the particles is achieved (after $\sim 150 \mathrm{~s}$ from activation of the aerosol generator). $C_{0}$ and $C$ represent respectively the concentrations of the particles measured before and after filtration, respectively. The FE values range from 0 to 1 (also expressed in percentage), meaning no particles or all of the particles are sequestered from the air stream, respectively. The output of the particle analyzer is the particle distribution of the aerosol (number of particles per volume per diameter vs particle diameter) over time. Therefore, both $C_{0}$ and $C$ are functions of the particle size, and consequently also the FE. Each test lasts $4 \mathrm{~min}$ in total. $C$ is calculated by taking the average over $30 \mathrm{~s}$ from $150 \mathrm{~s}$ to $180 \mathrm{~s}$. Afterward, from 180 to $240 \mathrm{~s}$, the valve is switched (Figure 1, 10) in order to measure the concentration of the unfiltered air, and $C_{0}$ is calculated by averaging the concentration values detected by the analyzer over this time frame. The temperature and relative humidity of the aerosol after reaching steady state were $24{ }^{\circ} \mathrm{C}$ and $25 \%$, respectively.

Pressure Drop. The pressure drop $(\Delta P)$ and airflow were measured using a water differential manometer and flowmeters, respectively. For further extrapolations of $\Delta P$ at different flow velocities, a second-grade polynomial fitting equation was obtained from the data points using Origin.

\section{RESULTS AND DISCUSSION}

SEM micrographs (Figure 2A-C) of the PLA-PA11 filter show that the distribution of the nanofibers on the PLA support is not perfectly homogeneous, with deposition of the electrospun PA11 more localized in the central part of the holes of the PLA mesh. This effect is likely due to the electrostatic nature of PLA, which caused inhomogeneity in the electric field around the substrate. Indeed, if the surfactant (TWEEN 80) is not used, this effect is magnified, causing the formation of big holes in the electrospun mat in the vicinity of the edges of the PLA mesh (data not shown).

The transparency of the filter material was quantified by measuring the transmittance in the visible-light range (400$700 \mathrm{~nm}$ ). In Figure 3A are reported the UV-vis spectra of the pressed and pristine PLA mesh, together with the PLA-PA11 filter. The filter has $72 \%$ transmittance at $\lambda=555 \mathrm{~nm}$, and the transmittance decreases with a decrease of the wavelength. Indeed, for light wavelengths below the size of the scattering fiber, the amount of scattering is inversely proportional to the fourth power of the wavelength (Rayleigh scattering). Therefore, the scattering is higher at a lower wavelength, and this trend is stronger for PLA-PA11, which contains nanofibers with an average diameter of $76 \pm 19 \mathrm{~nm}$.

The FE of the PLA-PA11 filter was tested mimicking the human breathing velocity at light physical exertion $(8 \mathrm{~cm} / \mathrm{s})$ according to the SNR 30000:2021 rule. ${ }^{18}$ More in detail, the rule SNR 30000:2021 is a normative document developed by The Swiss Association for Standardization, which is a member 

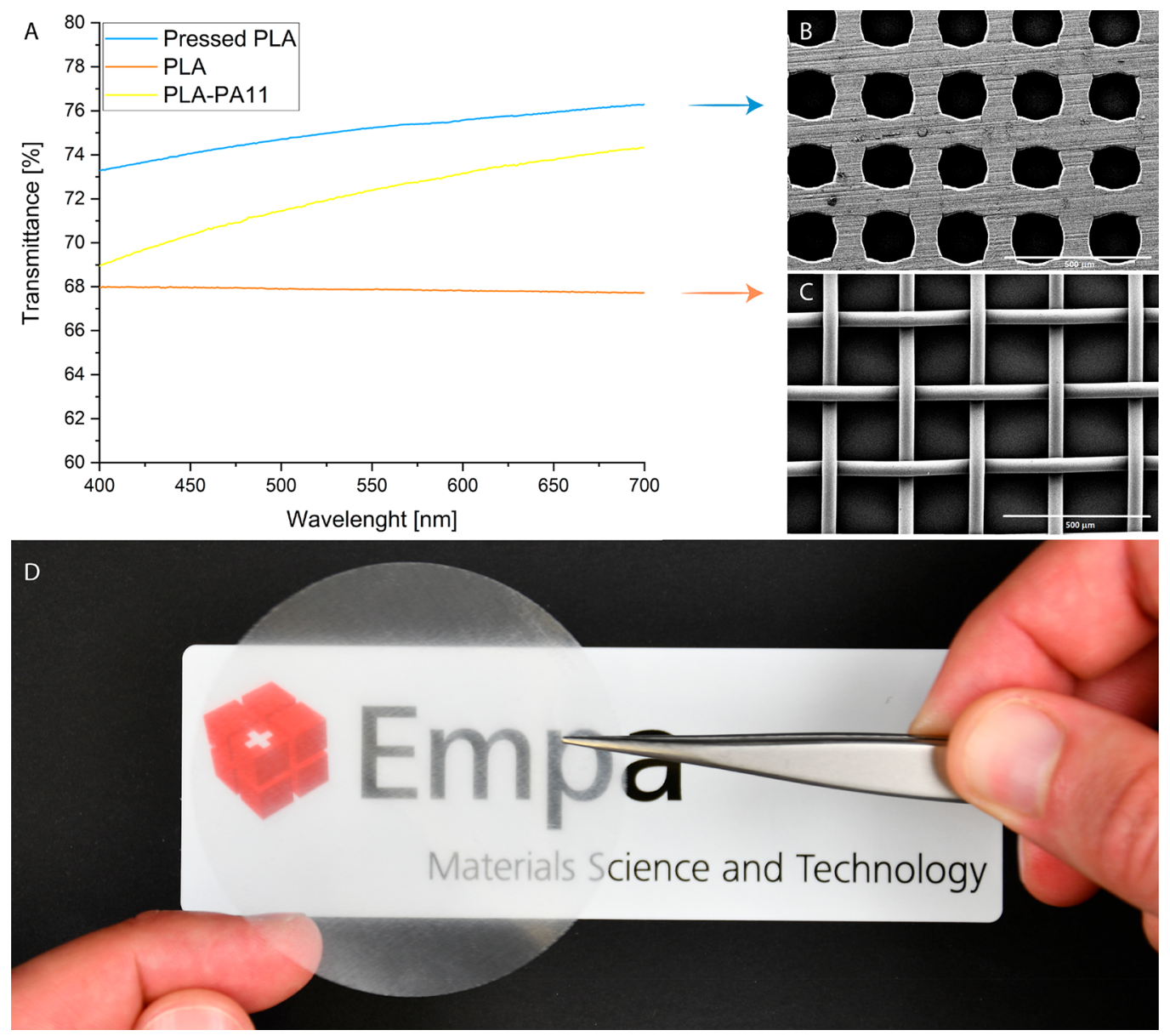

Figure 3. (A) UV-vis spectra of the pressed PLA mesh (blue), PLA-PA11 (yellow), and pristine PLA mesh (orange) with SEM micrographs of (B) pressed and (C) pristine PLA mesh. (D) Picture of the free-standing PLA-PA11 filter lifted about $5 \mathrm{~cm}$ from the Empa logo.

of the European Committee for Standardization and the International Organization for Standardization. The $\mathrm{SNR}^{18}$ is well achieved, valid for 5 years with an additional 3 years if transformed into a Swiss Standard. The SNR ${ }^{18}$ defined that the FE values at $1000 \mathrm{~nm}$ of all of the measurements shall be $\geq 0.70$ and any single measurement not less than 0.60 , using $\mathrm{NaCl}$ aerosol. ${ }^{18}$ In our study, PLA-PA11 showed FEs at 1000 $\mathrm{nm}$ of $0.84 \pm 0.03$ and $0.89 \pm 0.05$ for fructose and $\mathrm{NaCl}$ aerosols, respectively. The FE tests on PLA-PA11 were performed on four or five different samples, and the average FE values and standard deviations are reported in Figure 4. According to the results, the differences of FEs measured and calculated from both aerosols can be considered statistically significant (with a 5\% significance level) only from 20 to 42 $\mathrm{nm}$ and from 365 to $750 \mathrm{~nm}$. The statistical significance test was performed using "Welch's $t$ test" using Matlab software. Generally, the FE of the PLA-PA11 filter is $\sim 0.35$ in the range of $20-100 \mathrm{~nm}$ and increased from $\sim 0.4$ to $\sim 0.95$ in the range 100-1500 nm. The EN 14683:2019 norm outlines the use of an aerosol of bacterial suspension of Staphylococcus aureus for testing the FE performance of a medical face mask, which may not be fully comparable with the method used in this study. $S$. aureus bacteria have a diameter between 0.5 and $1 \mu \mathrm{m}$ with a tendency of forming clusters; ${ }^{22}$ thus, the size of the bacteria aerosol particle depends on the power and type of nebulizing technique. "Annex B" of the EN 14683:2019 norm states that the mean size of the particles has to be $3.0 \pm 0.3 \mu \mathrm{m} .{ }^{17}$ Therefore, we may assume that the overall bacterial FE

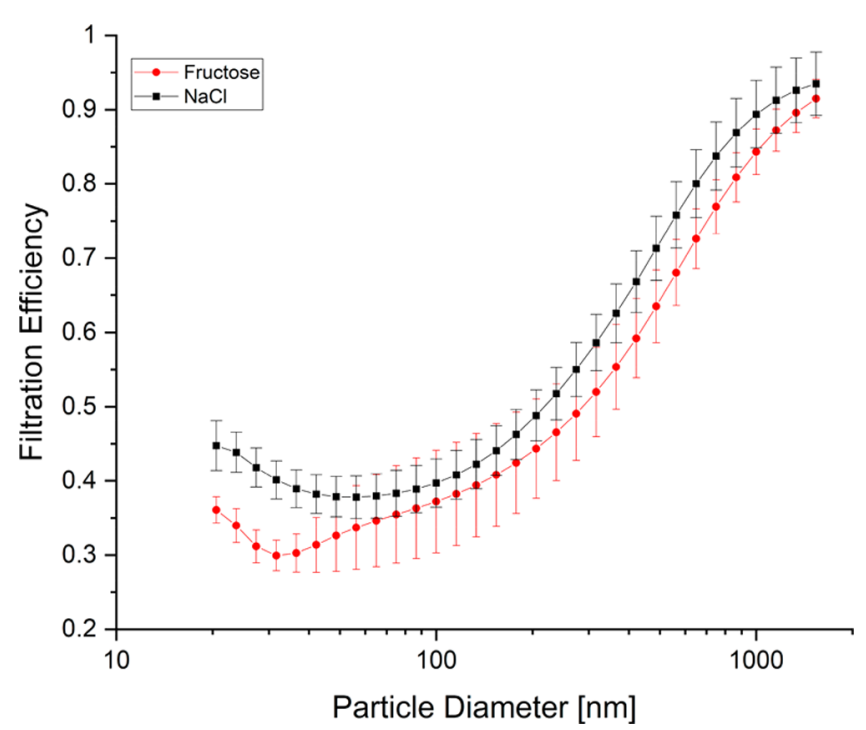

Figure 4. FE of PLA-PA11 calculated in the range $\sim 20-1500 \mathrm{~nm}$.

measured with $S$. aureus aerosol will be at least as good or even higher compared with our result (FE values at $1000 \mathrm{~nm}$ ) using $\mathrm{NaCl}$ and fructose particles.

SEM micrographs of PLA-PA11 after $4 \mathrm{~min}$ of filtering against fructose (Figure $2 \mathrm{D}-\mathrm{F}$ ) and $\mathrm{NaCl}$ (Figure 2G-I) aerosols are also reported. The high hygroscopic nature of 
fructose particles causes the merging of neighboring particles. This is also reported elsewhere using wetting liquid aerosols. ${ }^{10}$

Differences of pressure across the filter called pressure drop $(\Delta P)$, normalized by the filter area $\left(4.9 \mathrm{~cm}^{2}\right)$, upon specific conditions of airflow $(11,23,34,45,57,68,85,113$, and 170 $\mathrm{cm} / \mathrm{s}$ ) are reported in Figure 5. $\Delta P$ and the airflow were

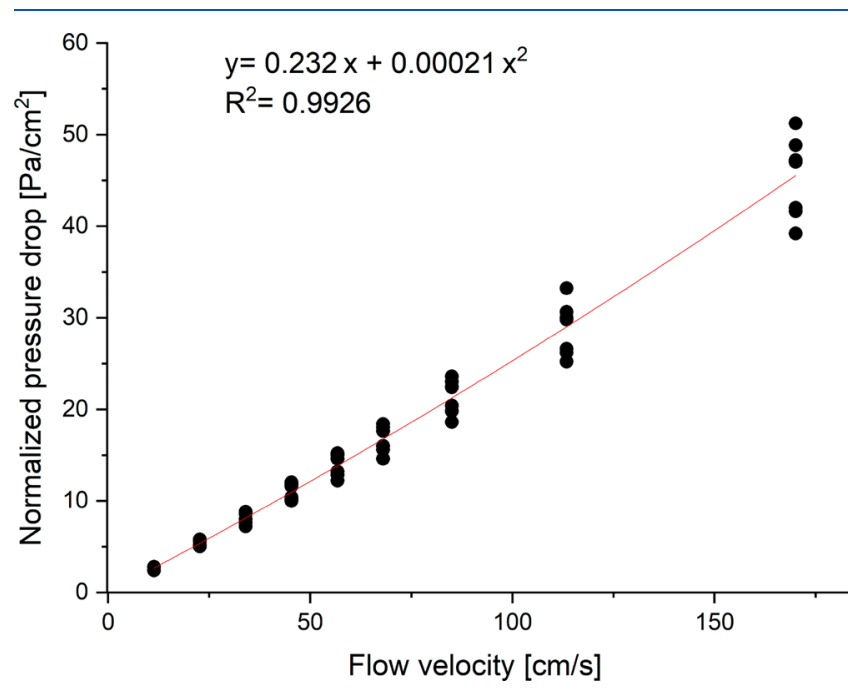

Figure 5. Experimental values of the normalized pressure drop at different flow velocities (black dots) of PLA-PA11. The red curve represents the best-fit equation together with $R^{2}$.

measured on six samples. $\Delta P$ is an important parameter that specifies the comfort of the worn mask. According to the standard norm EN 14683:2019, the limit of $\Delta P$ for a medical face mask is $40 \mathrm{~Pa} / \mathrm{cm}^{2}$ for type I and II masks and $60 \mathrm{~Pa} / \mathrm{cm}^{2}$ for a type IIR mask measured with a flow velocity of $27 \mathrm{~cm} / \mathrm{s}$. In our case, the pressure drop of PLA-PA11 at $27 \mathrm{~cm} / \mathrm{s}$ was extrapolated to be only $6.5 \mathrm{~Pa} / \mathrm{cm}^{2}$, whereas the pressure drop of the PLA mesh was only $0.3 \mathrm{~Pa} / \mathrm{cm}^{2}(\Delta P$ values of PLA mesh are reported in Figure S2). Moreover, because $\Delta P$ remained constant after a flow rate of $170 \mathrm{~cm} / \mathrm{s}$ was applied for several minutes, the test confirmed that the PA11 nanofibers are stable enough to withstand mechanical solicitation caused by sneezing $(120-150 \mathrm{~cm} / \mathrm{s})$.

\section{CONCLUSION}

The prepared PLA-PA11 was shown to be the perfect candidate for the production of transparent masks with very low pressure drop (easy to breathe through), resistance to high flow velocity (sneezing), and good filtration properties against aerosol of $1 \mu \mathrm{m}$ diameter or bigger. Moreover, because the PA11 nanofibers are directly electrospun onto a plastic freestanding substrate and through a needleless setup, ${ }^{23}$ the production procedure has the potential to allow for industrial upscale.

\section{ASSOCIATED CONTENT}

\section{SI Supporting Information}

The Supporting Information is available free of charge at https://pubs.acs.org/doi/10.1021/acsanm.1c02843.

Distribution of the generated $\mathrm{NaCl}$ and fructose particles (PDF)

\section{AUTHOR INFORMATION}

\section{Corresponding Author}

René M. Rossi - Empa, Swiss Federal Laboratories for Materials Science and Technology, Laboratory for Biomimetic Membranes and Textiles, 9014 St. Gallen, Switzerland; ○ orcid.org/0000-0003-0946-682X; Email: Rene.Rossi@ empa.ch

\section{Authors}

Joshua Avossa - Empa, Swiss Federal Laboratories for Materials Science and Technology, Laboratory for Biomimetic Membranes and Textiles, 9014 St. Gallen, Switzerland; (1) orcid.org/0000-0003-3758-986X

Till Batt - Empa, Swiss Federal Laboratories for Materials Science and Technology, Laboratory for Biomimetic Membranes and Textiles, 9014 St. Gallen, Switzerland

Thierry Pelet - EPFL, Ecole Polytechnique Fédérale de Lausanne, EssentialTech Centre, 1015 Lausanne, Switzerland; HMCARE SA, Campus Biotech Innovation Park, 1202 Geneva, Switzerland

Sacha P. Sidjanski - EPFL, Ecole Polytechnique Fédérale de Lausanne, School of Life Sciences SV-DO, 1015 Lausanne, Switzerland

Klaus Schönenberger - EPFL, Ecole Polytechnique Fédérale de Lausanne, EssentialTech Centre, 1015 Lausanne, Switzerland

Complete contact information is available at: https://pubs.acs.org/10.1021/acsanm.1c02843

\section{Author Contributions}

The manuscript was written through the contributions of all authors. All authors have approved the final version of the manuscript.

\section{Funding}

The project "HelloMask: Transparent Medical Face Mask" was funded by "Innosuisse-Swiss Innovation Agency" (Grant ID 5211.01751), which is an entity promoting science-based innovation in the interests of industry and society in Switzerland.

Notes

The authors declare no competing financial interest.

\section{ACKNOWLEDGMENTS}

The authors want to thank Gebert Rüf Stiftung, Giuseppe Kaiser Stiftung, Fondation ProTechno, Fondation Jacqueline Cornaz, Fondation Hubert Tuor, a foundation advised by CARIGESTFondation Coromandel, Fondation Assura, Fondation Baur, and InnoSuisse.

\section{REFERENCES}

(1) Lu, T.; Cui, J.; Qu, Q.; Wang, Y.; Zhang, J.; Xiong, R.; Ma, W.; Huang, C. Multistructured Electrospun Nanofibers for Air Filtration: A Review. ACS Appl. Mater. Interfaces 2021, 13 (20), 23293-23313.

(2) Alexander, C. The City as a Mechanism for Sustaining Human Contact. In People and Buildings; Gutman, R., Ed.; Taylor \& Francis, 2009; p 29.

(3) He, H.; Gao, M.; Illés, B.; Molnar, K. 3D Printed and Electrospun, Transparent, Hierarchical Polylactic Acid Mask Nanoporous Filter. Int. J. Bioprinting 2020, 6 (4), 1-9.

(4) Kim, M. W.; An, S.; Seok, H.; Yoon, S. S.; Yarin, A. L. Electrostatic Transparent Air Filter Membranes Composed of Metallized Microfibers for Particulate Removal. ACS Appl. Mater. Interfaces 2019, 11 (29), 26323-26332. 
(5) Kim, M. W.; An, S.; Seok, H.; Yarin, A. L.; Yoon, S. S. Transparent Metallized Microfibers as Recyclable Electrostatic Air Filters with Ionization. ACS Appl. Mater. Interfaces 2020, 12 (22), $25266-25275$.

(6) Mikheev, A. Y.; Shlyapnikov, Y. M.; Kanev, I. L.; Avseenko, A. V.; Morozov, V. N. Filtering and Optical Properties of Free Standing Electrospun Nanomats from Nylon-4,6. Eur. Polym. J. 2016, 75, 317328.

(7) Liang, W.; Xu, Y.; Li, X.; Wang, X. X.; Zhang, H. D.; Yu, M.; Ramakrishna, S.; Long, Y. Z. Transparent Polyurethane Nanofiber Air Filter for High-Efficiency PM2.5 Capture. Nanoscale Res. Lett. 2019, 14 (1), DOI: 10.1186/s11671-019-3199-0.

(8) Liu, H.; Huang, J.; Mao, J.; Chen, Z.; Chen, G.; Lai, Y. Transparent Antibacterial Nanofiber Air Filters with Highly Efficient Moisture Resistance for Sustainable Particulate Matter Capture. iScience 2019, 19, 214-223.

(9) Xu, J.; Liu, C.; Hsu, P. C.; Liu, K.; Zhang, R.; Liu, Y.; Cui, Y. Roll-to-Roll Transfer of Electrospun Nanofiber Film for HighEfficiency Transparent Air Filter. Nano Lett. 2016, 16 (2), 12701275.

(10) Xia, T.; Chen, C. Toward Understanding the Evolution of Incense Particles on Nanofiber Filter Media: Its Influence on PM2.5 Removal Efficiency and Pressure Drop. Build. Environ. 2020, 172, 106725.

(11) Cao, J.; Cheng, Z.; Kang, L.; Lin, M.; Han, L. Patterned Nanofiber Air Filters with High Optical Transparency, Robust Mechanical Strength, and Effective PM2.5capture Capability. RSC Adv. 2020, 10 (34), 20155-20161.

(12) Cui, J.; Lu, T.; Li, F.; Wang, Y.; Lei, J.; Ma, W.; Zou, Y.; Huang, C. Flexible and Transparent Composite Nanofibre Membrane That Was Fabricated via a "Green" Electrospinning Method for Efficient Particulate Matter 2.5 Capture. J. Colloid Interface Sci. 2021, 582, 506-514.

(13) Wang, X.; Xiang, H.; Song, C.; Zhu, D.; Sui, J.; Liu, Q.; Long, Y. Highly Efficient Transparent Air Filter Prepared by CollectingElectrode-Free Bipolar Electrospinning Apparatus. J. Hazard. Mater. 2020, 385, 121535 .

(14) Liu, C.; Hsu, P. C.; Lee, H. W.; Ye, M.; Zheng, G.; Liu, N.; Li, W.; Cui, Y. Transparent Air Filter for High-Efficiency PM 2.5 Capture. Nat. Commun. 2015, 6, DOI: 10.1038/ncomms7205.

(15) Lv, S.; Zhao, X.; Shi, L.; Zhang, G.; Wang, S.; Kang, W.; Zhuang, X. Preparation and Properties of Sc-PLA/PMMA Transparent Nanofiber Air Filter. Polymers (Basel, Switz.) 2018, 10 (9), 996.

(16) Cheng, Z.; Cao, J.; Kang, L.; Luo, Y.; Li, T.; Liu, W. Novel Transparent Nano-Pattern Window Screen for Effective Air Filtration by Electrospinning. Mater. Lett. 2018, 221, 157-160.

(17) European Committee for Standardization (Brussels). Requirements and Test Methods; English Version EN 14683:2019 + AC:2019, English Translation of DIN EN 14683:2019-10, 2019.

(18) Swiss Association for Standardization. Community MasksBasic Requirements and Test Procedures, Swiss Rule SNR30000:2021, 2021.

(19) Meireman, T.; Daelemans, L.; Rijckaert, S.; Rahier, H.; Van Paepegem, W.; De Clerck, K. Delamination Resistant Composites by Interleaving Bio-Based Long-Chain Polyamide Nanofibers through Optimal Control of Fiber Diameter and Fiber Morphology. Compos. Sci. Technol. 2020, 193, 108126.

(20) Alder, C. M.; Hayler, J. D.; Henderson, R. K.; Redman, A. M.; Shukla, L.; Shuster, L. E.; Sneddon, H. F. Updating and Further Expanding GSK's Solvent Sustainability Guide. Green Chem. 2016, 18 (13), 3879-3890.

(21) Video of single-wire needleless electrospinning from Elmarco, https://www.youtube.com/watch?v=IRc120Ceq9o (accessed July 2, 2021).

(22) Gnanamani, A.; Hariharan, P.; Paul-Satyaseela, M. Staphylococcus Aureus: Overview of Bacteriology, Clinical Diseases, Epidemiology, Antibiotic Resistance and Therapeutic Approach. In Frontiers in Staphylococcus aureus; Enany, S., Alexander, L. E. C., Eds.; IntechOpen: Rijeka, Croatia, 2017; DOI: 10.5772/67338.
(23) Iranshahi, K.; Luisier, N.; Schoeller, J.; Chung, M.; Hashemizadeh, S.; Fortunato, G.; Defraeye, T.; Rossi, R. M. Improving Wire-Based Electrospinning Throughput by Tailoring Solution Properties with Additivesle. Mater. Des. 2021, unpublished paper. 